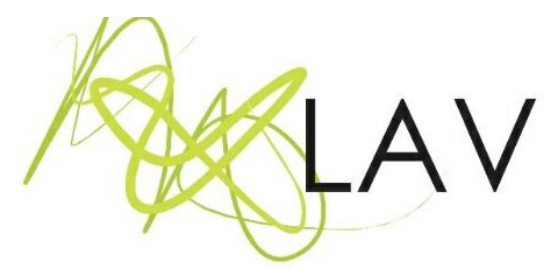

\title{
Cinema e educação: atravessamentos de práticas de fascismo e nomadismo no filme "O substituto"
}

Cinema and education: crossings of fascism and nomadism practices in the movie "The substitute"

\author{
Mirele Corrêa \\ Universidade Estadual de Campinas \\ Alexandrina Monteiroii \\ Universidade Estadual de Campinas
}

\section{Resumo}

Este ensaio tem por objetivo discutir práticas de fascismo e nomadismo presentes no filme "O Substituto", cujo título original em inglês é Detachment (indiferença), relacionando-as aos processos educativos da contemporaneidade. O filme nos coloca a pensar práticas educacionais que giram em torno da temática da diferença em sala de aula e de suas contradições. A indiferença pode ser tomada com o prefixo 'in' que 'nega' a diferença enquanto uma singularidade imanente do indivíduo, produzindo fascismos e universais, mas também o 'in' que se refere ao 'movimento para dentro'. Propõe-se, neste trabalho, um exercício de pensamento antropofágico da (in)diferença, que insurge a negação da mesma, fazendo proliferar tratados de nomadologia contra unificações. Nômade também é o professor 'substituto', aquele que não se fixa no território da clausura escolar, mas que, no movimento de substituições, possibilita rupturas com o fora, para se pensar uma educação menor que tenciona microrrevoluções cotidianas, contribuindo com a emersão de outras existências.

Palavras-chave: escola, educação menor, diferença, fascismo, nomadismo.

\begin{abstract}
The text aims to discuss the practices of fascism and nomadism present in the film "O Substituto", concatenating the contemporary educational processes. With its original English title "Detachment" (indifference), the film makes us think about educational practices that revolve around the theme of difference in the classroom and its contradictions. Indifference can be taken with the prefix 'in' which 'denies' the difference as an immanent singularity of the individual producing fascisms and universals, but also the 'in' which refers to the 'inward movement'. We propose an exercise in anthropophagic thinking of (in) difference, which denies it, causing nomadology treaties to proliferate against unification. Nomad, too, is taken as the "substitute" teacher. The one who does not settle in the territory of the school enclosure, but who in the movement of substitutions, allows breaks with the outside, to think about a smaller education that intends to daily micro-revolutions, making other existences emerge.
\end{abstract}

Keywords: school, minor education, difference, fascism, nomadism. 


\section{Um filme, mil pensamentos... Deslocamentos}

"E nunca me senti tão profundo ao mesmo tempo, tão indiferente de mim mesmo e tão presente no mundo".

(Albert Camus)

O que nos leva a pensar é um encontro com o problema, que faz emergir o pensamento, uma emanação do caos. Se Deleuze (1990) afirmava que o cinema é a arte do pensamento, logo podemos tomá-lo como um disparador na produção de algo que nos inquieta e nos coloca em enfrentamento com o mundo ou, consonante a Camus, coloca-nos presentes no mundo e em contato direto com a sua complexidade.

"Sei como é importante ter alguém que nos ajude a compreender a complexidade do mundo em que vivemos", pondera o professor Henry Barthes, interpretado por Adrien Brody, no filme "O Substituto", dirigido pelo cineasta britânico Tony Kaye em 2011, logo na primeira cena. O diretor faz uma composição de imagens em que a narrativa transita entre a história e o relato de professores em estilo documental. A construção desse enredo nos mobiliza a discutir diversas questões que atravessam a escola, principalmente no que concerne aos fascismos que assombram as relações entre professor e aluno no território crítico e caótico em que se encontra a escola pública, quando esta, abandonada e negligenciada pela comunidade escolar, necessita encontrar maneiras para subverter as dificuldades da deriva. Ademais, o que poderia ser apreendido no encontro com o filme é que o caos e a violência do mundo reverberam em cada um de múltiplas formas, mas todos estão condenados a seu enfrentamento.

Conforme explicam Deleuze e Guattari (2010, p. 139-40),

[o] caos define-se menos por sua desordem que pela velocidade infinita com o qual se dissipa toda forma que nele se esboça. É um vazio que não é um nada, mas um virtual, contendo todas as partículas possíveis e suscitando todas as formas possíveis que surgem para desaparecer logo em seguida, sem consistência nem referência, sem consequência. É uma velocidade infinita de nascimento e esvanecimento.

O protagonista do longa, professor Henry Barthes, é aquele que, no movimento do cotidiano, necessita enfrentar o caos do seu passado com o avô e a mãe, que o aterroriza em memórias da infância todas as vezes que ele volta ao hospital para prestar cuidados ao avô doente. Enfrenta o caos, ao fornecer ajuda a uma adolescente leviana, tirando-a da rua e da prostituição, oferecendo-Ihe abrigo em sua casa e passando a ser responsável por ela ao criar toda uma relação de afeto. Ao assumir aulas como professor

Revista Digital do LAV - Santa Maria - vol. 14, n. 1, p. 73 - 88 - jan./abr. 2021 ISSN 1983 - 7348 http://dx.doi.org/10.5902/1983734863198 
substituto de literatura, ele se defronta com o caos de uma escola pública conflagrada, tendo que encarar uma turma de alunos alheios ao abandono e à diligência dos pais, vítimas do descaso da sociedade. Alunos descrentes de si e potencialmente agressivos uns com os outros precisam aprender a lidar com os antagonismos e as diferenças de cada um na clausura da sala de aula. Barthes enfrenta o nascimento e o esvanecimento do caos a cada dia.

Todos temos problemas, todos temos coisas com que estamos lidando, certo? E todos nós os levamos para casa conosco à noite. Levamos ao trabalho conosco de manhã. Acho que aquele desamparo, aquela percepção, aquele pressentimento de estar à deriva no mar, sem boia ou rede de segurança...quando achou que seria você que jogaria a boia [Henry Barthes].

O filme se passa nesses três ambientes: casa, hospital e escola, mas é nesse último que o cineasta coloca em evidência os maiores dilemas e impasses que afetam todas as personagens presentes no contexto escolar. Ele estrutura a narrativa de uma forma tão invasiva que faz com que o próprio espectador se sinta afetado por certa impotência e desamparo. Quando Barthes chega à escola para lecionar por um mês, ele se depara com uma instituição com problemas financeiros e estruturais: a diretora é constantemente ameaçada a pedir exoneração do cargo; os demais professores, com a saúde mental já fragilizada, tomam atitudes completamente inaceitáveis e desmedidas com os alunos por não encontrarem outra saída frente à falta de compromisso dos mesmos e ao descaso dos pais; os alunos agridem a si e os professores verbal e fisicamente, usando o bullying como estratégia de produção do outro, do qual se pode expelir as frustrações, medos e indiferenças.

O título do filme original em inglês Detachment pode ser traduzido por 'indiferença', justamente porque o filme nos dá a impressão de uma estratégia de distanciamento, afastamento, ou seja, de uma tentativa de não afetação e envolvimento do professor substituto com os sujeitos e com as questões escolares, tendo em vista todas as problemáticas que ele já carrega. O próprio Barthes confessa "eu passo muito tempo tentando não me comprometer de fato". Entretanto, há algo nessas relações, nesses enfrentamentos com o caos, com o passado, com o cotidiano, nesses encontros com o outro, nesses saltos microfascistas, que dão pistas para pensar e ver outras coisas acontecendo. Há algo no 'entre' que vibra e nos dá certa esperança que não se deixa sufocar por uma interpretação niilista e nem conformativa da vida. Há algo nesse escrachamento da realidade que faz pensar em outros possíveis modos de agir de uma existência menos exposta às macroviolências do mundo e mais potente nos esconderijos,

Revista Digital do LAV - Santa Maria - vol. 14, n. 1, p. 73 - 88 - jan./abr. 2021 ISSN 1983 - 7348 http://dx.doi.org/10.5902/1983734863198 
nas fugas, quiçá nas estratégias nômades. Há algo nessa 'indiferença de si' que faz com que nos tornemos mais presentes no mundo e profundos em nós de outros jeitos.

\section{(In)diferença: 'entre' fascismo e nomadismo}

Se pensar, para Deleuze e Guattari (2010, p. 53), é "seguir a linha de fuga do voo da bruxa", ou conforme a tradução inglesa, a line of light, linha de voo, neste texto queremos traçar dois movimentos de sobrevoo que atravessam as questões entre indiferença, fascismo e nomadismo concatenado aos processos educativos que o filme nos mobiliza e provoca: um que se encontra na (in)diferença como produtora de uma maquinaria fascista; outro na (in)diferença como agenciadora de um tratado de nomadologia.

\section{Sobre a indiferença como uma maquinaria fascista}

A indiferença aqui pode ser tomada em dois sentidos. Primeiro, a indiferença em si, enquanto uma ação, um ato de não envolvimento, de distanciamento de determinadas situações ou indivíduos, uma demonstração de falta de interesse ou desdém a algo ou alguém. Mas, também, se analisada pelo uso do prefixo 'in', que nega algo, podemos pensar em uma negação da diferença, uma in-diferença, non difference.

A diferença que trazemos ao debate é o ponto central da filosofia deleuziana. Quando falamos em diferença, não nos referimos ao diverso, à diversidade. A diferença é o que faz com que o diverso seja diverso. Ela nada tem a ver com o diferente. A redução da diferença ao diferente equivale a uma redução da diferença à identidade. A diferença é intensiva e está na ordem do sensível - o ser do sensível -, por isso não pode ser apreendida pela representação. Toda obra de Deleuze é direcionada na tentativa de romper com a representação clássica do pensamento, pois apenas por meio dessa ruptura que o pensamento é liberado de sua função recognitiva e potencializado de maneira criadora. A diferença é um acontecimento do próprio ser, ou seja, é o modo como ele se expressa e se diz. A diferença condiz com a singularidade do ser e não pode ser estabelecida quando obedece a critérios representativos (SCHÖPKE, 2012).

Os dois sentidos propostos - de (in)diferença como afastamento e de (in)diferença como negação -, são indissociáveis, um opera no/com o outro. Quando eu nego a diferença, por consequência, eu me afasto. No entanto, junto ao afastamento também emerge um novo movimento: a produção do Outro por meio da sua fixação numa identidade. Essa produção é agenciada pela máquina aparelho de Estado que tem 
por objetivo a conservação e a perpetuação de seus órgãos de poder, operando, conforme Deleuze e Guattari (2012, p. 12), "por liame mágico, tomada ou captura imediata: não combate e não tem máquina de guerra, ele liga e isso é tudo".

A escola, instituição alinhada à lógica do aparelho de Estado, desde sua invenção no século XVII, pauta-se na representação. A representação se apoia em um modelo, em um padrão, forçando o pensamento a chegar sempre a uma mesma forma, a uma finalização. Carvalho e Gallo (2010) argumentam que a representação é uma máquina binária, que

[opera] no fluxo do significado-significante, angariando padrões, deslocando os pensamentos, as ações, os desejos, as condutas, por intermédio de finalizações e de sentidos que são avalizados pela reprodução do Mesmo. A representação pauta-se pela intensificação da experiência qualitativa; aprofunda-se em um sentido proposto a partir de uma força que se impõe e que também se verticalizará; dá as costas para quantidades de experiências que ameacem quebrar o seu aprofundamento linear na relação do que está representado (CARVALHO, GALLO, 2010, p. 284).

Dentro dessa lógica de representação, a escola consegue medir seus resultados e avaliar suas práticas, garantindo a produção de corpos cada vez mais conformados a uma identidade alinhada ao sistema econômico vigente. A escola conduz o pensamento por meio de suas metodologias pedagógicas. Parte de um ponto determinado " $x$ " para chegar num ponto " $y$ ", e tudo que foge, escapa ou percorre outro caminho dessa linha dura, molar, já não corresponde ao que ela espera. Assim, todo desvio é tido como transgressor, anormal, uma vez que opera em outra lógica e resiste ao controle da mesma, que escapa a sua condução, fugindo da norma (CORRÊA, 2017).

De forma a evitar desvios, o aparelho de Estado engendra políticas públicas educacionais que vão capturar condutas e modos de ser, por meio da fixação de identidades. Os discursos que circulam de "diversidade" nas Diretrizes Curriculares Nacionais são exemplos dessa estratégia política, que visa adequar todos os "diferentes" dentro de uma norma de inclusão sob um manto de igualdade, que por si só já é exclusiva. A identidade está para a diversidade, assim como a diferença está para a multiplicidade. Conforme Silva (2002, p. 66),

[a] identidade é predicativa, propositiva: $x$ é isso. A diferença é experimental: o que fazer com x. A identidade é da ordem da representação e da recognição: $x$ representa $y, x$ é $y$. A diferença é da ordem da proliferação; ela repete, ela replica: x e y e z... A identidade tem negócios com o artigo definido: o, a. A diferença, em troca, está amasiada com o artigo indefinido: um, uma. A

Revista Digital do LAV - Santa Maria - vol. 14, n. 1, p. 73 - 88 - jan./abr. 2021 ISSN 1983 - 7348 http://dx.doi.org/10.5902/1983734863198 
diferença não tem a ver com a diferença entre $x$ e $y$, mas com o que se passa entre $\mathrm{x}$ e $\mathrm{y}$. A identidade joga pelas pontas; a diferença, pelo meio. A identidade é. A diferença devém.

Os discursos contemporâneos sobre diversidade implicam a produção de um Outro diferente de mim. Ou seja, implicam na conformação do outro numa identidade que não é a minha, não é aquilo na qual eu me identifico. O Outro é aquele transformado, inventado e fabricado exclusivamente como um alvo de todas e cada uma das modalidades de racismo.

O outro é um outro que nós não queremos ser, que odiamos e maltratamos, que separamos e isolamos, que profanamos e ultrajamos, mas que utilizamos para fazer de nossa identidade algo mais confiável, mais estável, mais seguro; é um outro que tende a produzir uma sensação de alívio diante unicamente de sua invocação (SKLIAR, 2016, p. 75-6).

Skliar (2016, p. 66) afirma que todas as ações culturais quando criam populações identitárias ou categorias de diversidade, como o negro, o homossexual, o deficiente, o indígena, na verdade, estão dirigindo suas ações "a uma violenta construção diferencial do outro" que está muito longe de ser igualitária. Essa catalogação identitária, que vai ampliando seus limites de captura toda vez que algo "anormal", emerge é uma forma de garantir o controle e a segurança do território, uma vez que o modelo previne desvios, desformidades e microrrevoluções.

Segundo Foucault (2008b), a população se instaura como uma nova estratégia política moderna a partir do século XVIII. Já não interessa mais os indivíduos ou grupos, séries de indivíduos isoladamente, e sim a população enquanto objetivo, instrumento ou meio para se obter algo. O que determina a administração da melhor maneira possível da população são os comportamentos dos indivíduos que se inserem como elementos dessa estratégia de governo. Essa população é evidentemente composta por indivíduos perfeitamente diferentes uns dos outros e dependentes de toda uma série de variáveis para se identificar o universal e, no interior dele, ser capaz de agir e modificá-lo.

Populações dos comportados e dos não comportados, dos qualificados e dos não qualificados, dos incluídos e dos excluídos, identificando todos dentro de um agrupamento e permitindo que se produza um saber possível sobre cada um deles. Foucault (2008a) afirma que "é a partir da constituição da população como correlato das técnicas de poder que pudemos ver abrir-se toda uma série de domínios de objetos para saberes possíveis" (FOUCAULT, 2008a, p. 103). Só é possível um controle quando se sabe a quem controlar.

Revista Digital do LAV - Santa Maria - vol. 14, n. 1, p. 73 - 88 - jan./abr. 2021 ISSN 1983 - 7348 http://dx.doi.org/10.5902/1983734863198 
Neste esboço da noção de população enquanto uma economia de poder, o povo se coloca como uma divisória, que, de maneira geral, resiste à regulação da população. O povo é aquele que tenta escapar desse dispositivo pelo qual a população existe, ele tenta se colocar de fora, recusando-se a ser população e desajustando o sistema (FOUCAULT, 2008b). O corpo que se faz povo não é o que resta da população quando capturada, e sim o que está sempre em movimento de entrada e saída, oscilando entre um e outro, à espreita de qualquer suspeita de encarceramento das possibilidades de devir.

Contudo, como afirma Deleuze (2013), falta-nos o povo, assim como também nos falta a alteridade, conforme Skliar (2016). O autor afirma ser a modernidade a época da fabricação do outro:

A alteridade começa a estar ausente, começa a faltar, e resulta ser imperiosamente necessária a produção construtiva do outro como diferença. No entanto, trata-se de uma construção artificial, que se fundamenta numa erosão das singularidades das culturas (SKLIAR, 2016, p. 66).

A diversidade como vem sendo trabalhada carrega um discurso moral e jurídico que absorve artificialmente uma palavra muito disseminada pela instituição escolar, eximindo toda distinção e aceitação das diferenças do outro: a tolerância. Esta palavra "trazida à tona pela vigente gramática multicultural, tem ressoado com particular rapidez e eficácia [...] para sublinhar uma posição claramente antirracial" (SKLIAR, 2016, p. 69).

A tolerância, assim como a liberdade e a democracia, configura-se num dispositivo de segurança na atual sociedade de biopolítica, descrita por Foucault (2008b). Ela não está ali para normalizar, disciplinar posturas ou resolver um problema por meio de um sistema de legalidade. A tolerância reforça a violência e inferioriza a diferença, num jogo de superiorizar um e diminuir o outro.

A tolerância não inclui a aceitação do valor do outro: pelo contrário, é novamente, talvez de maneira mais sutil e subterrânea, a forma de reafirmar a inferioridade do outro e serve de antessala à intenção de acabar com a sua especificidade - junto com o convite ao outro de cooperar na consumação do inevitável. A tão falada humanidade dos sistemas tolerantes não vai além de concernir o adiamento do conflito final (BAUMAN, 1996, p. 82).

A tolerância nega a singularidade e a multiplicidade inominável do outro, "ao fazer do outro um outro parecido, mas um outro parecido e nunca idêntico a nós mesmos" (SKLIAR, 2016, p. 74). Por isso, podemos dizer com segurança que toda essa maquinaria que envolve questões da (in)diferença (enquanto negação), da diversidade e da identidade e que atravessam a escola afetando diretamente a constituição dos indivíduos

Revista Digital do LAV - Santa Maria - vol. 14, n. 1, p. 73 - 88 - jan./abr. 2021 ISSN 1983 - 7348 http://dx.doi.org/10.5902/1983734863198 
é uma maquinaria fascista. É fascista, porque lida com o único, o verdadeiro, o universal, - modelo; centraliza-se nos investimentos capitalistas, na constituição de individualismos, na dissipação dos coletivos, na pulverização de violências em nível de exclusão. É fascista, porque aprisiona o indivíduo num corpo identitário; aliena a uma representação do mesmo; fecha às possibilidades de devir-outro; castra o desejo; extingue as multiplicidades; e esteriliza a pulsão revolucionária.

Entre outras formas de fascismo exibidas no filme, talvez a que mais se aproxima das questões em torno da identidade/diferença no contexto escolar é o bullying. A narrativa gira em torno de uma estudante que sofre constantes perseguições e deboches dos colegas por ser obesa e desajeitada. Dos pais, ela enfrenta diversas intimidações e cobranças por gostar de fotografia e por não querer estudar os cursos hegemônicos que garantem uma ascensão econômica e social. A personagem, no decorrer do filme, dá vários indícios de sua problemática, como de quem clama por ajuda, até se deparar com o professor Barthes e ver nele uma motivação para continuar resistindo aos fascismos. Barthes, por meio da palavra e da escuta, tenta de toda forma recuperar o que havia se perdido nela, num exercício de empatia e alteridade: "Somos todos iguais. Todos sentimos dor. Todos temos o caos em nossas vidas". Entrementes, ao perceber que o sentimento que ela construiu por ele não fora correspondido de igual maneira, ela se desespera e, imbuída por outras frustrações, tira a própria vida. Gallo (2013) defende que "só a morte vence o caos, só não há caos quando já não há nada" (GALLO, 2013, p. $50)$.

\section{Sobre a indiferença como agenciadora de um tratado de nomadologia}

No 'entre' ao que viemos pensando anteriormente, a (in)diferença como uma negação e um afastamento, queremos aqui pensar o prefixo 'in' na sua outra possibilidade de uso e significação, o 'in' referindo-se ao 'movimento para dentro'. E diante disso buscarmos um exercício de pensamento antropofágico da (in)diferença, que se insurge na negação da mesma, fazendo proliferar tratados de nomadologia contra unificações.

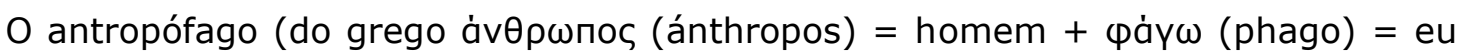
como) é literalmente aquele que se alimenta da carne humana, que devora partes de outro ser de sua mesma espécie. O que justifica essa prática está menos para a mitigação do desejo que para a ritualística que envolve tal acontecimento. Alimentar-se 
de carne humana é um exercício ascético, cujo aquele que pratica adquire toda a força, as habilidades e a virilidade daquele que é comido.

A antropofagia implica numa (in)corporação do outro, análogo a isso, o prefixo 'in' tem como referência o 'movimento de pôr para dentro', e diante disso, propomos, metaforicamente um exercício antropofágico da (in)diferença. Ou seja, comer a diferença, devorar a diferença, colocá-la para dentro de nós. Mas se a diferença é o princípio constitutivo de todos os indivíduos, ela está em cada um como sendo primeira em singularidade e intensidades. Assim, devorar a diferença implica a devoração do Outro, ou melhor, a in-corpo-(r)-ação do Outro - a ação de colocar o corpo do outro para dentro de nós.

Tendo em vista que a diferença tem a capacidade de se multiplicar, a antropofagia da (in)diferença é um banquete. Não devoramos UNO, mas múltiplos. Devorar é sair da dicotomia entre eu e outro, entre diferença e identidade. Devora-se não para procurar identificação nem reconhecimentos, mas para nos saciar com a multiplicidade, fazendo composições, conexões, individuações... devorar para devir-outro. Devorar para transformar os elementos externos como sendo seus. Ao devorar o Outro, colocamos para dentro um território-outro. Essa ação antropofágica se constitui em movimentos e fluxos intensivos, pois incorporamos a cada nova refeição uma nova Terra. Num movimento contínuo de territorialização e desterritorialização. Desse modo, a antropofagia da (in)diferença pode se constituir como uma máquina de guerra nômade e uma máquina de guerra contra a forma-Estado, atual ou virtual e seus agenciamentos fascistas de unificação.

Segundo Deleuze (2013), a máquina de guerra e o aparelho de Estado não pertencem às mesmas linhas. A máquina de guerra é definida como um agenciamento linear que se constrói sobre linhas de fuga de maior declive, vindas do fundo da estepe ou do deserto, enquanto que o aparelho de Estado pertence às linhas de segmentaridade dura, e até mesmo as condiciona ao efetuar a sua sobrecodificação.

Ironicamente, o objeto da máquina de guerra não está na guerra propriamente dita, mas no espaço-tempo que ela ocupa e se propaga. Enquanto que o aparelho de Estado codifica e descodifica o espaço, a máquina de guerra territorializa e desterritorializa, faz do fora um território no espaço, "uma outra justiça, um outro movimento, um outro espaço-tempo" (DELEUZE; PARNET, 1998, p. 14). A máquina de guerra foge, no entanto, ao fugir busca outras armas, podendo ser artística ou revolucionária, muito mais que guerreira (DELEUZE; PARNET, 1998). 
Inversamente, o poder de Estado repousa sobre o exercício das máquinas binárias que nos atravessam e da máquina abstrata que nos sobrecodifica: toda uma "política" (DELEUZE; PARNET, 1998, p. 163). Essa política penetra nas tessituras do currículo escolar, forçando os processos educativos a produzir verdades, instaurar padrões, homogeneizar condutas por meio das normalizações, que vão "esmagando e denunciando como nocivo tudo o que pertence a um pensamento sem imagem, ao nomadismo, à máquina de guerra, aos devires [...]" (DELEUZE; PARNET, 1998, p. 2122). Com sua rigidez, tal política nos assegura num território, numa população, numa subjetividade, num muro de significações dominantes. Esse muro, conforme Deleuze e Parnet (1998) é

[...] onde se inscrevem todas as determinações objetivas que nos fixam, nos enquadram, nos identificam e nos fazem reconhecer [...]. O Estado, sempre que possível, empreende um processo de captura sobre fluxos de toda sorte, de populações, de mercadorias ou de comércio, de dinheiro ou de capitais (DELEUZE; PARNET, 1998, p. 59, 63).

E ainda podemos acrescentar os fluxos educacionais que, desde muito cedo, por meio do controle, da vigia, da disciplina, da seleção dos conteúdos, dos discursos de igualdade e diversidade, da norma, atuam sobre o corpo, produzindo efeitos.

Diante disso, a antropofagia da (in)diferença pode se constituir como uma máquina de guerra nômade contra as políticas de Estado, operando um contrafluxo aos discursos de diversidade no contexto escolar. Ao devorar o outro, infiltra-se na máquina outra lógica de pensamento da diferença, na qual sobrepuja-se a alteridade e o agenciamento de outrens, combatendo as políticas homogeneizadoras de currículo que apresentam uma potência exímia de apropriação. Deleuze e Guattari (2012) confirmam que o aparelho de Estado se apropria de tudo, inclusive da máquina de guerra, subordinando-a a fins políticos.

Então, o que nos resta? Como transitar no território escolar sem cair nas malhas da captura? Como antropofagizar na clandestinidade? Como nos tornar imperceptíveis de maneira a poder agir sem ser visto e agir de outras formas? O filme nos dá algumas pistas, das quais podemos nos arriscar a pensar o professor 'substituto' como uma arma de guerra nômade, ou ainda, como um antropófago. Barthes sustenta uma figura ambígua do professor substituto, colocando o espectador em cinesia nessas duas faces que condicionam sua postura.

De um lado, o filme apresenta uma cristalização da imagem do professor substituto enquanto aquele que vez ou outra aparece para substituir o professor efetivo 
da disciplina que, por alguma razão, não pode dar a sua aula. Por isso, a presença dessa personagem na escola é vista quase sem significância nenhuma, porque, como passageiro, ele desconhece os reais problemas da instituição escolar e não tem tempo para se afetar com o território e muito menos conseguir afetar alguém. O substituto é só aquele que está aí para tapar um buraco, passar o conteúdo, entrar e sair, sem se envolver com as pessoas e/ou as tensões que abarcam a instituição de ensino. Isso fica evidente na cena da contratação do professor, quando a diretora adverte: "preocupe-se somente com o programa, é o mais importante".

Por outro lado, consideramos que o substituto tem ainda uma face de potência clandestina, visto que, devido a sua passagem pela escola, muitas vezes aligeirada, ele pode interferir na lógica do funcionamento escolar, infiltrando um 'vírus' sem ser visto. E aí, toda a cristalização de sua imagem se estilhaça, porque o substituto, da sua insignificância, passa a se configurar como uma arma potente da máquina de guerra. $\mathrm{O}$ substituto, na maioria dos casos, não conhece a escola, nem as pessoas que ali trabalham, tampouco os alunos. Do mesmo jeito que ele é um estranho para a escola, a escola também é estranha para ele. Nesse cenário, as relações acabam por se configurar de outra maneira. Há sempre um olhar curioso sobre o estrangeiro - principalmente por parte dos alunos, pois ele acaba sendo alguém novo que traz coisas novas -, e um olhar curioso do estrangeiro sobre o novo território que vai adentrar. Podemos dizer, parafraseando a fala da diretora da escola no momento da entrevista com Barthes, que ele é o professor da 'margem', da fronteira, na qual as coisas se confundem, ou ainda, um professor de um não-lugar e, portanto, sempre um forasteiro.

Barthes agia clandestinamente. Observava tudo, afastava-se dos problemas que não Ihe convinham, não se aproximava de qualquer pessoa, mantinha mínimas relações com outros professores, estudava seus alunos, suas posturas, escolhia a melhor maneira para chegar até eles. Era um nômade a todo o momento mapeando os desejos e os afetos, ocupando e deslocando os espaços, fazendo emergir outros espaços-tempos... agia para, conforme Deleuze e Guattari (2012, p. 109), "fazer crescer o deserto, a estepe, não despovoá-los, pelo contrário", por isso, era visto como indiferente, insignificante. Mas lá no fundo da sua (in)diferença ele fazia brotar outras coisas. Pela antropofagia, estabelecia agenciamentos determinando traços diferenciais na sua conduta, que na clausura e solitude da sala de aula invocava caminhos, "que são outras tantas vias do afeto; nesses caminhos, aprende-se a 'desservir-se' das armas tanto quanto servir-se delas [...]. Aprender a desfazer e a desfazer-se é o próprio da máquina de guerra: o 'não-fazer' do guerreiro, desfazer o sujeito" (DELEUZE; GUATTARI, 2012, p. 
85). Desfazer o sujeito e encontrar maneiras de sobreviver ao sufocamento do Estado, por meio do pensamento.

Barthes colocava o pensamento em relação imediata com o fora, com as forças do fora, em suma, fazia do pensamento uma máquina de guerra, quando, por exemplo, ao discutir a literatura sombria de Edgar Allan Poe, forçava os alunos a lidarem com seus medos e frustrações. Impelia-os a enfrentar o caos, chocando-os às dificuldades insuportáveis que, na maior parte das vezes, eram vertidas por meio da violência. Esse exercício de escuta e alteridade fazia fluir afetos e perceptos, dando condições mais sensíveis às relações e vivências em sala de aula. "O que importa não é nem vencer o caos, nem fugir dele, mas conviver com ele e dele tirar possibilidades criativas" (GALLO, 2013, p. 49).

Barthes inventava outros mundos invocando o pensamento, o que somente sua condição de nômade possibilita. O nômade é esse que carrega consigo um povoado, que no ato da antropofagia vai agenciando e alimentando-se de tribos pelos caminhos que atravessa. O nômade não se fixa no território da clausura escolar e nos movimentos de substituições, de territorializar e se desterritorializar, vai possibilitando rupturas com o fora para se pensar um novo. O nômade só existe dessa forma, em devir e em interação (DELEUZE; GUATTARI, p. 2012), aí é que está sua potência revolucionária. Ele é capaz de fazer outra escola no interior da mesma escola (GALLO, 2015), mas não só.

Essa potência revolucionária possibilita um devir que Gallo (2013) chama de professor-militante. Tornar-se um professor-militante é se imbuir de uma postura subversiva que permite ao nômade, do seu próprio deserto, do seu próprio terceiro mundo operar ações de transformação. O professor-militante não é denominado assim por fazer parte de um partidarismo político. Ele é militante, como afirma Negri (2001), pois é capaz de viver até o limite as misérias do mundo, de identificar as novas formas de exploração e de sofrimento, de engajar-se numa luta pela miséria do outro, que não é somente social, econômica, mas afetiva, emocional e psicológica. É por meio de um engajamento militante que se pode organizar processos de libertação contra todas as estratificações que nos colocam diante de fascismos e reféns deles.

Barthes é esse professor-militante que, ao antropofagizar o Outro, sente até o limite suas dores, suas misérias, seus desafetos, sente a pulsação instaurada do caos. Diante de sua própria miséria humana busca cavar buracos, abrir brechas, para que de alguma forma encontre espaços de oxigenação, pois como ele sempre enfatiza "tudo vai ficar bem". O militante é estrategista e age na surdina, porque não precisa de alardes 
para se fazer ouvir. Suas atitudes direcionam-se corpo a corpo, relação de afecto e percepto... puro desejo e transformação.

Há uma cena, em que Barthes, no intervalo da aula, recebe a visita de Meredith a menina que fotografava - e ganha um presente dela: uma montagem fotográfica. "Um homem sem rosto em uma sala vazia", exclama Barthes, impressionado com a visão de Meredith sobre ele: "É assim que você me vê?". "Não sei como te vejo", responde a garota. O substituto é talvez a possibilidade da impercepção que procuramos?

O substituto não estava preocupado em seguir as demandas do currículo escolar, menos ainda, em operar a favor das linhas sobrecodificação do aparelho de Estado. Não Ihe interessava condicionar o pensamento à representação e nem convencê-los de que o discurso de diversidade é o que produz a igualdade. O substituto estava antes engajado em outras políticas, uma política para vida ou de vida, uma micropolítica do desejo. Em razão disso, a clandestinidade, as deambulações, a militância. Era esse modo de ser e de habitar o território que o munia com armas para agir contra o Estado e seus fascismos, tencionando o currículo com microrrevoluções imperceptíveis na produção de uma outra estética da educação, impelindo nossos desejos para a produção de uma outra estética de nós mesmos.

\section{O que vaza do filme?}

"Você pode me ver, mas sou invisível". (Henry Barthes)

Deleuze (1987, p. 30) afirmava que o mais importante do que o pensamento é aquilo que faz pensar. Assim, apostamos no cinema como uma potência do pensamento. O filme "O substituto" nos possibilitou diversos deslocamentos, problematizações, múltiplas saídas. Com ele, pudemos traçar algumas linhas a respeito dos processos educativos da contemporaneidade, principalmente no que concerne aos fascismos embrenhados nas políticas de currículo sobre diversidade que mais fazem produzir violências do que minimizá-las, que mais excluem do que incluem.

O filme mobilizou nosso pensamento em torno das questões da (in)diferença. A (in)diferença que nega e afasta o outro, produzindo fascismos e universais, bem como a (in)diferença que devora o outro, por meio de um exercício antropofágico, fazendo proliferar tratados de nomadologia contra unificações. 
Diante disso, podemos dizer que a antropofagia da (in)diferença se constitui como uma máquina de guerra do povo contra a população e num ato revolucionário, cuja potência está na implosão da máquina fascista dos universais. Ela (im)plode num movimento de negação e afastamento, num movimento de dentro ao fora o fascismo, que, como afirma Foucault (1993), está em cada um de nós.

Outra proposta do ensaio girou em torno da ideia de considerar o professor 'substituto', um antropófago nômade. Aquele que não se fixa no território da clausura escolar, mas que no movimento de substituições e devorações, vai possibilitando rupturas com o fora para se pensar um novo para a escola, ou ainda, uma educação imperceptível que tenciona microrrevoluções cotidianas engajados na postura do professor-militante e impelindo nossos desejos para uma produção criativa e benéfica à vida.

O filme não se esgota nessas problematizações e as problematizações não se esgotam em si mesmas. Não há limites para o pensamento, porque é no próprio atravessamento da linha limítrofe que o pensamento é possível. E o que nos vazam são possibilidades, algumas saídas para inquietações que nos impelem, que nos movimentam e desassossegam.

Um filme que nos toca deixa 'vazar-se', ou talvez em sua explosão transborde em potência e desafia nossa capacidade de pensar. O substituto - lugar que tantas vezes ocupamos numa escola - problematiza esse (não) lugar do professor, problematiza a potência do vazio que se transforma na (in)diferença que o atravessa. E, é no contrapelo dessa (in)diferença, ou seja, é na antropofagia da diferença que sua força emerge e nos ensina que a luta não deve ter como meta vencer o caos, mas viver nele, como afirma Gallo (2013), conviver com ele para criar outras possibilidades. Sem dúvida, acreditamos ser esse o grande desafio que a educação contemporânea nos impõe.

Por fim, este estudo nos instiga a afirmar que o cinema combinado à educação pode impulsionar voos, pode fazer fugir o pensamento, extravasar novas ideias... nos faz vazar, nos faz fugir, nos faz extravasar em um novo devir.

\section{Referências}

BAUMAN, Z. Modernidad y ambivalência. In.: BERIAIN, J. (Comp.). Las consequências perversas de la modernidade. Barcelona: Anthropos, 1996. 
CARVALHO, A. F. de; GALLO, S. Do sedentarismo ao nomadismo: intervenções para pensar e agir de outros modos na educação. Educ. Tem. Dig., Campinas, v. 12, n. 1, p. 280-302, jul./dez. 2010

CORRÊA, M. O que pode um corpo na escola?: uma cartografia das potencialidades do corpo em espaço de escolarização. 2017. 121 f., il. Dissertação (Mestrado em Educação) - Programa de Pós-Graduação em Educação, Centro de Ciências da Educação, Universidade Regional de Blumenau, Blumenau, 2017. Disponível em: <http://www.bc.furb.br/docs/DS/2017/362383_1_1.pdf>. Acesso em: 12 mar. 2021.

DELEUZE, G. Conversações (1972-1990). Tradução de Peter Pál Pelbart. São Paulo: Editora 34, 3. ed. 2013.

DELEUZE, G. Foucault. Tradução de Claudia Satn'Anna Martins. São Paulo: Editora Brasiliense, 2013b. p. 142.

DELEUZE, G. A imagem-tempo: Cinema 2. Tradução Eloisa de Araújo Ribeiro. Revisão filosófica de Renato Janine Ribeiro. São Paulo: Editora Brasiliense, 1990. p. 338.

DELEUZE, G. Proust e os signos. Rio de Janeiro: Forense, 1987.

DELEUZE, G.; GUATTARI, F. Mil Platôs: Capitalismo e Esquizofrenia 2. v. 5. Tradução de Peter Pál Pelbart e Janice Caiafa. 2. ed. São Paulo: Editora 34, 2012, p. 264.

DELEUZE, G.; GUATTARI, F. O Anti-Édipo: capitalismo e esquizofrenia 1. Tradução de Luiz B. L. Orlandi. 2. ed. São Paulo: Editora 34, 2011, p. 560.

DELEUZE, G.; GUATTARI, F. O que é filosofia? Tradução de Bento Prado Jr. e Alberto Alonso Muñoz. 3. ed. São Paulo: Editora 34, 2010, p. 272.

DELEUZE, G.; PARNET, C. Diálogos. Tradução de Eloisa Araújo Ribeiro. São Paulo: Editora Escuta, 1998.

FOUCAULT, M. Segurança, território e população: curso dado no Còllege de France (1977-1978). Tradução de Eduardo Brandão; revisão de Claudia Berliner. São Paulo: Martins Fontes, 2008a.

FOUCAULT, M. Nascimento da biopolítica: Curso dado no Collège de France (19781979). Edição estabelecida por Michel Senellart sob a direção de François Ewald e Alessandro Fontana. Tradução de Eduardo Brandão. São Paulo: Martins Fontes, 2008b.

FOUCAULT, M. O Anti-Édipo: uma introdução à vida não fascista. Prefácio a edição americana de $\mathrm{O}$ anti-édipo. Capitalismo e esquizofrenia, de Gilles Deleuze e Félix Guatarri. Tradução de Cadernos de Subjetividades do Programa de Estudos PósGraduados em Psicologia Clínica da PUC-SP. v. 1, n. 1 (1993), p. 197-200. São Paulo: 1993.

FOUCAULT, M. Vigiar e Punir: Nascimento da Prisão. Tradução de Raquel Ramalhete. 38 ed. Petrópolis: Vozes, 2010.

GALLO, S. Pensar a escola com Foucault: além da sombra da vigilância. In: CARVALHO, A. F. de.; GALLO, S. (orgs.). Repensar a educação: 40 anos após Vigiar e Punir. São Paulo: Editora Livraria da Física, 2015.

GALLO, S. Deleuze \& a Educação. 3. ed. Belo Horizonte: Autêntica Editora, 2013.

Revista Digital do LAV - Santa Maria - vol. 14, n. 1, p. 73 - 88 - jan./abr. 2021 ISSN 1983 - 7348 http://dx.doi.org/10.5902/1983734863198 
NEGRI, A. Exílio. São Paulo: Iluminuras, 2001, p. 23-24.

PELBART, P. P. O avesso do Niilismo: cartografias do esgotamento. São Paulo: n-1 edições, 2. ed. 2016, p. 445.

SCHÖPKE, R. Por uma filosofia da diferença: Gilles Deleuze, o pensador nômade. 1. reimpr. Rio de Janeiro: Contraponto, 2012.

SILVA, T. T. da. Identidade e Diferenças: Impertinências. Educação \& Sociedade, ano XXIII, n. 79, ago./2002.

SKLIAR, C. A materialidade da morte e o eufemismo da tolerância: duas faces entre as milhões de faces, desse monstro (humano) chamado racismo. In.: GALLO, S.; SOUZA, G. M. de (orgs.). Educação do preconceito: ensaios sobre poder e resistência. Campinas: Editora Alínea, 2016, 2. ed. p. 61-80.

SKLIAR, C. Desobedecer a linguagem. Tradução de Giane Lesse. 1. ed. Belo Horizonte: Autêntica Editora, 2014.

SKLIAR, C. Y si el otro no estuviera ahí? Notas para uma pedagogia (improbable) de la diferencia. Buenos Aires: Miño y Dávila, 2002.

SPINOZA, B. de. Ética. Tradução de Tomaz Tadeu. 2. ed. Belo Horizonte: Autêntica Editora, 2017.

\footnotetext{
' Doutoranda em Educação na Universidade Estadual de Campinas - UNICAMP. Graduada em Pedagogia pela Universidade Regional de Blumenau - FURB (2012). Mestre em Educação pela Universidade Regional de Blumenau - FURB (2017). Integrante do Grupo de Pesquisa Políticas de Educação na Contemporaneidade (FURB), do Grupo PHALA Educação, Linguagem e Práticas Socioculturais (UNICAMP) e do GRIITTE - Grupo de Investigação e Invenção em Teorias Transversais para a Educação (UNIFESP). Tem interesse por temáticas como currículo, políticas educacionais, gestão, formação docente, subjetividades. Pesquisa a produção de subjetividades na escola contemporânea, com foco nas políticas de currículo neoliberais a partir da perspectiva da Filosofia da Diferença.

ii Possui graduação em Matemática pela Pontifícia Universidade Católica de Campinas (1989). Mestrado em Educação Matemática pela Universidade Estadual Paulista Júlio de Mesquita Filho (1992). Doutorado em Educação (1998) e Pós-doutorado em Filosofia da Educação (2015) pela Universidade Estadual de Campinas. Atualmente é professora e pesquisadora da Faculdade de Educação da Universidade Estadual de Campinas. Participa dos grupos de pesquisa Phala. Tem experiência de pesquisa na área de Educação (do ensino fundamental ao superior) com ênfase em temas como: currículo, políticas públicas, etnomatemática, relações entre matemática e práticas culturais, na perspectiva da Filosofia da Diferença.
}

Como citar esse artigo:

CORRÊA, Mirele; MONTEIRO, Alexandrina. Cinema e educação: atravessamentos de práticas de fascismo e nomadismo no filme "O substituto". Revista Digital do LAV, Santa Maria: UFSM, v. 14, n. 1, p. 73-88, jan./abr. 2021.

Revista Digital do LAV - Santa Maria - vol. 14, n. 1, p. 73 - 88 - jan./abr. 2021 ISSN 1983 - 7348 